\title{
Imaging of the Overhead Throwing Athlete
}

\author{
Hugue Ouellette, M.D., F.R.C.P.C., ${ }^{1}$ Ara Kassarjian, M.D., F.R.C.P.C., 1 \\ Patrice Tétreault, M.D., ${ }^{2}$ and William Palmer, M.D. ${ }^{1}$
}

The publisher regrets a typographical error in the name of Patrice Tétreault in the above article in Seminars in Musculoskeletal Radiology, Volume 9, Number 4, 2005, p. 316. The corrected spelling appears above.

${ }^{1}$ Department of Radiology, Massachusetts General Hospital, Harvard Medical School, Boston, Massachusetts; ${ }^{2}$ CHUM-Hôpital NotreDame, Department of Orthopedic Surgery, University of Montreal, Montreal, Quebec, Canada.

Address for correspondence and reprint requests: Hugue Ouellette, M.D., F.R.C.P.C., Department of Radiology, Massachusetts General Hospital, Harvard Medical School, 55 Fruit Street, Yawkey 6th Floor,
Boston, MA 02114.

Sports Specific Injuries; Guest Editor, Lawrence M. White, M.D., F.R.C.P.C.

Semin Musculoskelet Radiol 2007;11:91-92. Copyright (C) 2007 by Thieme Medical Publishers, Inc., 333 Seventh Avenue, New York, NY 10001 USA. Tel: + 1(212) 584-4662.

DOI 10.1055/s-2007-984733. ISSN 1089-7860. 